\title{
Taxus baccata intoxikazioa
}

\author{
Taxus baccata inoxication
}

Beñat de Alba Iriarte ${ }^{1 *}$, Eva Lorea Gil Rodriguez ${ }^{1}$, Edurne Bereciartua Urbieta ${ }^{1}$, Maria Elena Redin Sarasola ${ }^{1}$, Txoan Ormazabal Zabala ${ }^{2}$, Mikel Diez Bengoechea ${ }^{2}$, Maria Asuncion Vives Almandoz ${ }^{1}$, Adolfo Garrido Chercoles ${ }^{1}$, Oscar Quintela Jorge ${ }^{3}$.

${ }^{1}$ Donostia Unibertsitate Ospitaleko Analisi Klinikoen Zerbitzua

${ }^{2}$ Donostia Unibertsitate Ospitaleko Zainketa Intentsiboen Unitatea

${ }^{3}$ Espainiako Toxikologia eta Zientzia Forentseen Institutu Nazionala, Madrilgo

Departamentua, Kimika Zerbitzua

benat.dealbairiarte@osakidetza.eus

\section{Laburpena}

Taxus baccata munduko zuhaitz toxikoenetako bat da. Taxanoak eta alkaloide toxikoak dauzka: taxina da arriskutsuena. Landare ohikoa da gurean eta erabat arriskutsua izan daiteke; haatik, haginintoxikazioa nahiko bakana da. Kasuak nahita edo ezbeharrez gerta daitezke. Hortaz, gertaera susmagarrien orientazio eta diagnostiko azkarra egitea garrantzitsua da, arin artatzeko.

Kasu baten berri izan genuen. Gizonezko batek hagin-hosto ugari irentsi zuen suizidatzeko asmoz eta sintomarik gabe ospitaleratu zuten. Arnas alkalosia, konorte-galera eta takikardia bentrikularra jasan zituen ondoren. Urgentziaz tratatu zuten eta astebetean guztiz suspertu zen.

Ez dago intoxikazio hau orienta dezakeen alterazio analitiko espezifikorik. Laborategi klinikoetan ez da taxinaren konposatuen analisia egiten. Behin betiko diagnostikoa 3,5-dimetoxifenola (taxinaren metabolitoa) neurtuz konfirmatu zen, gas-kromatografia eta masa-espektrometria bidez. Laginak Toxikologia Institutuan analizatu ziren.

Gako-hitzak: 3,5-dimetoxifenola, hagina, intoxikazioa, kardiotoxikotasuna, taxina, Taxus baccata

\begin{abstract}
Taxus baccata is one of the most poisonous trees in the world. It contains taxanes and toxic alkaloids: the most dangerous one is the taxine. It is a fairly common plant in our environment and could be extremely dangerous; however, yew poisoning is quite rare. Cases may occur by voluntary or accidental form. Therefore, the rapid orientation and diagnosis of suspected episodes are important, in order to treat it quickly.
\end{abstract}

A man was transferred to the hospital with no symptoms after autolytic attempt by abundant yew leaves ingestion. He presented respiratory alkalosis, reduced consciousness and ventricular tachycardia. He was treated urgently and fully recovered in a week.

There are no specific analytical alterations in this intoxication. Taxine compound analysis is not made in clinical laboratories. The final diagnosis was confirmed by the detection of 3,5-dimethoxyphenol (a taxine metabolite), by gas chromatography-mass spectrometry. Samples were analyzed by the Institute of Toxicology.

Keywords: 3,5-dimethoxyphenol, yew, intoxication, cardiotoxicity, taxine, Taxus baccata

Bidalia: 2020.05 .18

Onartua: 2020.07.18

http://doi.org/10.26876/osagaiz.2.2020.308 
Beñat de Alba, Eva Lorea Gil, Edurne Bereciartua, Maria Elena Redin, Txoan Ormazabal, Mikel Diez, Maria Asuncion Vives, Adolfo Garrido, Oscar Quintela

\section{Taxus baccata: Heriotzaren zuhaitza}

Hagina (Taxus spp.) Taxaceae familiako zuhaitza da eta gune menditsu, fresko eta hezeetan ageri da. Espezie mota ugari daude eta horietako bat Taxus baccata da $(1,2)$.

Hagin arrunta (Taxus baccata) konifero bat da, jatorriz Europako mendebalde, hegoalde eta erdialdekoa eta Afrika iparraldekoa. Euskal Herrian 'hagin' izen soilaz ezaguna bada ere, Taxus generoko beste espezieetatik bereizteko 'europar hagin' izena ere erabiltzen da. Generoaren izena, Taxus, grekozko taxis hitzetik omen dator, eta hostoak ilaretan jartzeko erari egiten dio erreferentzia. Izen espezifikoa, baccata, latinezko bacca (baia) hitzetik dator, eta adierazten du baiak ematen dituela fruitutzat zuhaitzak.

Hosto iraunkorreko zuhaitza da, kono-itxura du eta 10-20 metro garai izan daiteke. Ale batzuk emeak dira eta besteak arrak. Enbor lodia eta leuna du, kolore arre-purpurakoa, eta 4 metroko diametroa izan dezake. Hostoak linealak eta puntazorrotzak dira, berde ilunak gainaldean eta argiagoak azpialdean. Loreak txikiak eta horiak dira. Egitura mamitsu gorri bizi batez (ariloa) inguratutako haziak dira fruituak (1. eta 2. irudiak). Haginaren atal guztiak (enborra, hostoak, loreak, haziak...), ariloa izan ezik, pozoitsuak dira.

1. eta 2. irudiak. Taxus baccata.
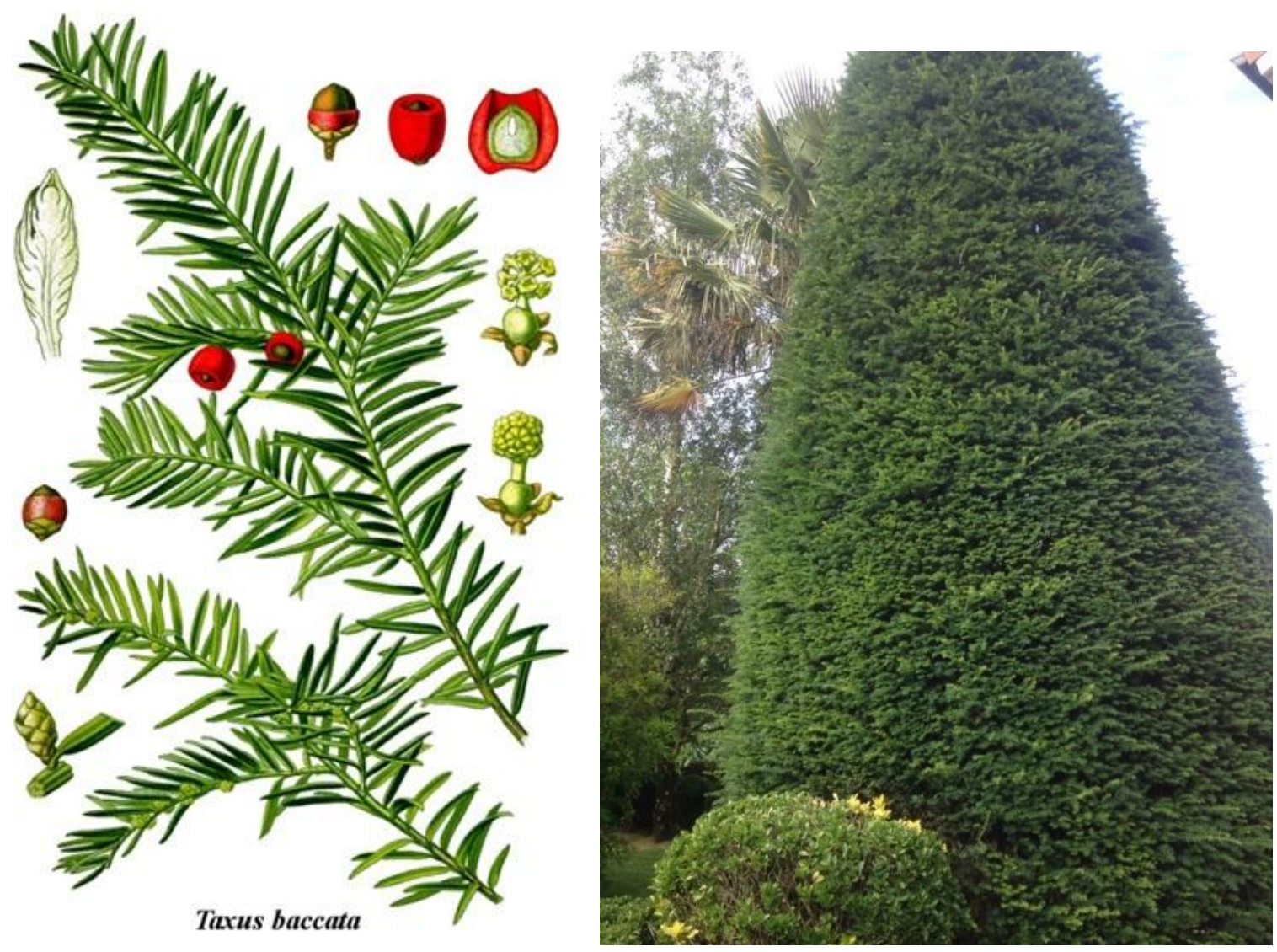

Munduko zuhaitz toxikoenetako bat da eta erabat arriskutsua izan daiteke: taxanoak eta alkaloide toxikoak dauzka. Taxanoetatik paclitaxel edo taxol gisako medikamentu antineoplasikoa lortzen da; alkaloide toxikoen artetik taxina da arriskutsuena, sodio- eta kaltzio-kanalen antagonista, eta efektu kardiotoxikoa du. Haatik, hagin-intoxikazioa nahiko arraroa da. Kasuak nahita edo ezbeharrez gerta daitezke. Hortaz, gertaera susmagarrien orientazio eta diagnostiko azkarra egitea garrantzitsua da, arin artatzeko.

Landare ohikoa da gurean. Eremu karstikoetan eta baso mistoetan ageri da. Arraroa da basoak osatzea, ohikoagoa da zuhaitz bakar gisa ikustea. Kasu gutxitan sortzen ditu benetako haginbasoak, baina badaude mota honetako hainbat baso gure inguruan. Hagin izena sarri agertzen 
da Euskal Herriko leku izenetan, garai batean ugariagoa zen seinale. Espezieak garrantzi handia hartzen du toponimian, ez bakarrik Euskal Herrian, baita Iberiar Penintsula guztian ere. Ezagunak dira Asturiasko Sueveko hagin-basoa, Palentziako Tosandekoa edo Zamorako "El texeduelo". Euskal Herrian Pagoetako natura-parkekoak dira handienak, baina badaude gehiago esate baterako Aralarren, Izkin, Trebiñun eta Gorbeian.

Antzina espezie desiratua zen, kalitate handiko zura eta propietate medizinalak eta pozoitsuak dauzkalako. Paleolitoan jada erabiltzen zen haginaren egurra hainbat lanabes eta tresna egiteko: orraziak, aizkora-kirtenak eta lantzak. Ezaguna da arkuak egiteko erabiltzen zela hagina, horretarako aparteko ezaugarriak baitzituen haren egurrak. Haren zura oso gogorra da eta zurgintzan oso estimatua izan da. Dirudienez, intentsiboki ustiatu denez egin du horrenbeste atzera zuhaitz honen populazioak eta, motel hazten denez, asko kostatzen da berreskuratzea. Dena den, munduan luzaroen bizi den zuhaitzetako bat da: 5.000 urte inguru iraun dezake.

"Heriotzaren zuhaitza" gisa ezagutzen zen greziar eta erromatar zibilizazioetan eta haginaren pozoiaz suizidatzea ohitura nahiko hedatua zen garai haietan. Euskal Herriko mitologiari nahiz mitologia zeltari estu loturiko zuhaitza da. Euskal Herriak zuhaitz sakratutzat hartu izan du hagina, eta hilen munduarekin lotu. Erritual batzuen parte zen, ziurrenik bere bizitza-luzera zela eta, hilezkorra baitirudi. Horregatik, Europako zati askotan hagin zahar bakarrak naturaren monumentu kontsideratzen dira eta babestuta daude.

Bitxikeria gisa, Gipuzkoako armarrian ageri diren ur gaineko hiru zuhaitzak hagin arruntak dira, gurean landare honek daukan garrantziaren seinale.

\section{Hagin-intoxikazioa}

Hagin (Taxus baccata) intoxikazioa oso arraroa da, baina gertatuz gero, oso larria edo hilgarria izan daiteke. Haginak taxina deritzon substantzia toxikoa dauka, zeharo arriskutsua: urdailhesteetako narritadura eta efektu kardiotoxikoak eragiten dituen alkaloide toxikoa da eta miozitoen sodio- eta kaltzio-kanalen antagonista izanik, bihotz-geldiketa ekar dezake dosi altutan (3). Dosi hilgarria 50-100 gramo hostotan neurtu da, eta zuhaitzetik eroritako adartxoak eta hostoak landare freskoa bezain toxikoak dira.

Hagin-intoxikazioaren sintomak orokorrean irenstetik ordubetera gertatu ohi dira eta neurologikoak (zorabioak, gihar-ahulezia, bertigoa) eta urdail-hesteetakoak (goragalea, beherakoa, sabeleko mina) izaten dira. Beranduago, midriasia, konbultsioak eta letargia ager daitezke, eta azkenik, alterazio kardiobaskularrak izateko arriskua dago, irenstetik hiru ordu pasa eta gero gutxi gorabehera (takikardia bentrikularra, fibrilazio bentrikularra eta bihotzgeldialdia). Heriotza kardiotoxikotasun akutuagatik gertatzen da. Hala ere, taxina bizkor xurgatzen denez, kasu batzuetan heriotzaren aurretik ez da sintomarik antzematen eta ez da hagin-intoxikazioaren susmorik ere izaten (4).

Ez dago intoxikazio hau orienta dezakeen alterazio analitiko espezifikorik. Diagnostikatzen zaila da, landare honen irensketa susmatzen ez bada (5). Diagnostiko diferentziala bihotzeko gaixotasunekin, eritasun neurologikoekin edo beste intoxikazio batzuekin egin behar da. Kasua orientatzeko garrantzitsuak dira anamnesi zorrotza eta pazientearen e do laguntzaileen aitortza, baita, intoxikazioaren benetako kausa zehazteko helburuz, laborategian taxinaren alkaloideak ikertzeko proba analitikoak egitea ere. 3,5-dimetoxifenol taxinaren metabolitoaren neurketa da behin betiko diagnostikoa konfirmatzeko era bakarra. Gas-kromatografia eta masaespektrometria bidez eduki gastriko, gernu- edo odol-laginetan bila daiteke $(6,7,8)$. Taxinaren lotura glukosidikoaren hausturagatik eratzen da eta haginaren edozein zatiren ondoriozko pozoitze-kasutan adierazle biokimiko erabilgarria dela frogatu da.

Harrigarriki, istripuz gertatzen diren irensketa gehienak asintomatikoak dira eta interbentzio txikia behar izaten dute bakarrik, edo ezer ez. Suizidio-saiakeretan, ordea, taxinak bihotztoxikotasun hilgarria sor dezake eta tratamendu zorrotzagoa behar izaten da. Literaturan 
agertzen diren kasu ezberdinetan aipatzen diren terapiei dagokienez onura oso txikia ikusi da; beraz, intoxikazio hauen aurrean erabil behar den tratamenduaren inguruan zalantza nabarmenak daude oraindik. Hagin-intoxikazioaren maneiua honetan datza gutxi gorabehera: oinarrizko neurri sintomatikoak, euste-terapia (oxigenoterapia eta bizi-zeinuen kontrola), urdail-hustutze azkarra (oka eraginez edo urdaileko garbiketa bidez), katartikoak edo libragarriak eta ikatz aktibatua. Bihotz-arritmiak zaintzea ere garrantzitsua da eta kasu larrietan aldi baterako taupada-markagailua ipintzen da (9).

Pronostikoa hartutako toxiko kopuruaren, anamnesi zuzenaren eta tratamendua ezarri arte irauten den denboraren araberakoa da.

\section{Kasuaren aurkezpena}

48 urteko gizonezkoak hagin-hosto ugari irentsi zuen bere buruaz beste egiteko asmoz. Egindakoaz damutu zen ordea, eta Larrialdi Zerbitzura deitu zuen. Anbulantzian eraman zuten ospitalera.

Sintomarik gabe ospitaleratu zuten eta Larrialdietako Zerbitzuan artatu zuten. Bertan miaketa egin zioten eta odol-analisiak eskatu zituzten. Azterketa fisikoa normala izan zen eta lehen odol-analisian arnas alkalosia soilik antzeman zioten.

Ustekabean, konorte-galera eta takikardia bentrikularra jasan zituen, eta kardiobertsio elektrikoa eta intubazio orotrakeala egin ondoren, Zainketa Intentsiboen Unitatera (ZIU) eraman zuten larri. Bigarren odol-analisian, parametro batzuen balioen igoera nabarmendu zen: leukozitoak $\left(20,96 * 10^{3} / \mu \mathrm{L}[3,8-10]\right)$, laktatoa $(4,66 \mathrm{mmol} / \mathrm{L}[<2])$, troponina $(19,3 \mathrm{ng} / \mathrm{L}[0-$ 14] eta kreatina kinasa (237 U/L [0-189]). Gainerako emaitzak normalak izan ziren.

Tratamenduan ikatz aktibatua, magnesio sulfatoa, amiodarona, euskarri basoaktiboa eta taupada-markagailua erabili ziren. 24 ordura egonkortasun klinikoa eta hemodinamikoa lortu zituen eta astebetean ondoriorik gabe guztiz suspertu zen.

Gizonezko honen odol-analisietan ez zen intoxikazioa ziurtatzeko alterazio espezifikorik aurkitu eta hortaz, hortaz ospitaleko laborategi klinikoan ez genuen haren diagnostikoa baieztatzerik izan. Horretarako haginaren taxina toxikoaren 3,5-dimetoxifenol metabolitoaren neurketa egin behar da eta toxikologia-gaietan espezializatuak diren erakundeetan egiten dituzte analisi horiek. Odolean metabolito hori aurkitzea nahikoa da hagin-intoxikazioa gertatu dela ziurtatzeko.

Kasuaren behin betiko diagnostikoa 3,5-dimetoxifenola neurtuz konfirmatu zen, gas-kromatografia eta masa-espektrometria bidez. Laginak Madrilgo Toxikologia Institutuan analizatu ziren eta 3,5dimetoxifenola detektatu zen.

\section{Ondorioak}

Euskal Herriak zuhaitz sakratutzat hartu izan du hagina. Landare ezaguna da gurean eta hilen munduarekin lotu izan da. Hagin-intoxikazioa arrunta ez bada ere, erabat arriskutsua izan daiteke alkaloide toxikoengatik eta haren hostoak jatea hilgarria izan daiteke. Autolisi-kasuak egoteaz gain, ezbeharrez gertatutakoak ere badira: haginarekin jolasean aritutako haurrak (10), haginaren magalean egondako animaliak (11), haginaren zura landutako arotzak (12), etab. Orokorrean, autolisi-kasuak hilgarriak izan ohi dira; ezbeharrez gertatutakoetan, berriz, sintoma arinagoak izaten dituzte. Ohikoa da hagina gure inguruko parkeetan eta basoetan ikustea eta beraz, kontuz ibiltzea komeni da.

Ez dago intoxikazio hau orienta dezakeen alterazio analitiko espezifikorik. Diagnostikatzen zaila da, landare honen irensketa susmatzen ez bada. Taxinak urdail-hesteetako narritadura, ondorio 
neurologikoak eta kardiotoxikotasuna eragiten ditu, eta dosi altuetan bihotz-geldialdia eta heriotza. Kasua orientatzeko anamnesi zorrotza egitea garrantzitsua da eta diagnostikoa konfirmatzeko 3,5dimetoxifenolaren neurketa egin behar da. Hagin-intoxikazio kasuak urriak direnez, proba hau ez da ospitaletako laborategi klinikoan egiten eta, susmoa egiaztatzeko, laginak Toxikologia Institutuan analizatzen dira. Arin artatu ezean, klinikak bilakaera tamalgarria izan dezake ordu gutxitan. Zorionez, gure pazientea onik atera zen.

\section{Eskerrak eta oharrak}

Lan hau Donostia Unibertsitate Ospitaleko Analisi Klinikoen Zerbitzuaren eta Zainketa Intentsiboen Unitatearen eta Espainiako Toxikologia eta Zientzia Forentseen Institutu Nazionaleko Madrilgo Departamentuko Kimika Zerbitzuaren arteko lankidetzari esker egin da.

\section{Erreferentzia bibliografikoak}

1. Arrizurieta I, Tubia I. Haginari balioa ematen [Internet]. Andoain: berria. 2014 [Kontsulta: 2020 04-23]. Eskuragarri: https://www.berria.eus/paperekoa/1812/046/001/2014-0930/haginari balioa ematen.htm

2. Thomas PA, Polwart A. Taxus baccata L [Internet]. J Ecol. 2003 [Kontsulta: 2020-04-23]; 91:489524. Eskuragarri: https://doi.org/10.1046/i.1365-2745.2003.00783.x

3. Piskač O, Střbrný J, Rakovcová H, Malý M. Cardiotoxicity of yew [Internet]. Cor et Vasa. 2015 [Kontsulta: 2020-04-23]; https://doi.org/10.1016/j.crvasa.2014.11.003

$57(3): 234-238$.

Eskuragarri:

4. Labossiere AW, Thompson DF. Clinical toxicology of yew poisoning [Internet]. Ann Pharmacother. 2018 [Kontsulta: 2020-04-23]; 52(6):591-599. Eskuragarri: https://doi.org/10.1177/1060028017754225

5. Reijnen G, Bethlehem C, vanRemmen JMBL, Smit HJM, vanLuin M, Reijnders UJL. Post-mortem findings in 22 fatal Taxus baccata intoxications and a possible solution to its detection [Internet]. J Forensic Leg Med. 2017 [Kontsulta: 2020-04-23]; 52:56-61. Eskuragarri: https://doi.org/10.1016/j.jfIm.2017.08.016

6. Froldi R, Croci PF, Dell'Acqua L, Farè F, Tassoni G, Gambaro V. Preliminary gas chromatography with mass spectrometry determination of 3,5-dimethoxyphenol in biological specimens as evidence of taxus poisoning [Internet]. J Anal Toxicol. 2010 [Kontsulta: 2020-04-23]; 34(1):5356. Eskuragarri: https://doi.org/10.1093/jat/34.1.53

7. Grobosch T, Schwarze B, Stoecklein D, Binscheck T. Fatal poisoning with Taxus baccata. Quantification of paclitaxel (taxol A), 10-deacetyltaxol, baccatin III, 10-deacetylbaccatin III, cephalomannine (taxol B), and 3,5-dimethoxyphenol in body fluids by liquid chromatographytandem mass spectrometry [Internet]. J Anal Toxicol. 2012 [Kontsulta: 2020-04-23]; 36(1):36-43. Eskuragarri: https://doi.org/10.1093/jat/bkr012

8. Kobusiak-Prokopowicz M, Marciniak A, Ślusarczyk S, Ściborski K, Stachurska A, Mysiak A, Matkowski A. A suicide attempt by intoxication with Taxus baccata leaves and ultra-fast liquid chromatography-electrospray ionization-tandem mass spectrometry, analysis of patient serum and different plant samples: case report [Internet]. BMC Pharmacol Toxicol. 2016 [Kontsulta: 2020-04-23]; 17(1):41. Eskuragarri: https://doi.org/10.1186/s40360-016-0078-5

9. Hernández Hernández JL, Quijano Terán F, González Macías J. Intoxicación por tejo [Internet]. Med Clin (Barc). 2010 [Kontsulta: 2020-04-23]; 135(12):575-576. Eskuragarri: https://doi.org/10.1016/j.medcli.2009.06.036

10. Riaño Galán I, Cobo A, López I, Garijo MG, Orejas G, Díaz C. Probable intoxicación por taxina: Presentación de dos casos [Internet]. An Esp Pediatr. 1998 [Kontsulta: 2020-04-23]; 49(2):211. Eskuragarri: https://www.aeped.es/sites/default/files/anales/49-2-25.pdf 
Beñat de Alba, Eva Lorea Gil, Edurne Bereciartua, Maria Elena Redin, Txoan Ormazabal, Mikel Diez, Maria Asuncion Vives, Adolfo Garrido, Oscar Quintela

11. Cortinovis C, Caloni F. Alkaloid-Containing Plants Poisonous to Cattle and Horses in Europe [Internet]. Toxins (Basel). 2015 [Kontsulta: 2020-04-23]; 7(12):5301-5307. Eskuragarri: https://doi.org/10.3390/toxins 7124884

12. Álvarez M. Inhalé tejo puliendo una rama y pasé las de Caín [Internet]. Santander: El Diario Montañés. 2013 [Kontsulta: 2020-04-23]. Eskuragarri:

https://www.eldiariomontanes.es/v/20130115/cantabria/inhale-tejo-puliendo-rama$\underline{20130115 . h t m l}$ 